\title{
COVID-19 and The Hidden Cost of Reduced Civil Liberties
}

Andy E. Williams

Nobeah Foundation, Nairobi, Kenya

Email: awilliams@nobeahfoundation.org

\begin{abstract}
The ongoing COVID-19 outbreak that emerged from Wuhan, China in 2020 has seen unprecedented restrictions on civilian populations in many countries in the attempt to curtail the spread of the pandemic. A recently developed model of general collective intelligence predicts the properties of group decision-making systems that are required to optimize collective outcomes, along with predicting that authoritarian systems of decision-making might tend to be restricted to non-optimal group outcomes in ways that are somewhat hidden in that they require an understanding of this new and relatively unknown model of general collective intelligence. In light of this model of general collective intelligence, the economic restrictions imposed to combat the pandemic take on a new light, since these restrictions have not only resulted in economic lockdowns for some countries, but in some cases have also effectively imposed martial law. The hidden cost of this reduction in civil liberties is explored from the perspective of the cost of an authoritarian decision-making system resulting in non-optimal group outcomes as theorized by this model of general collective intelligence, using models of government inefficiency to assess the cost of those non-optimal group outcomes, and therefore the hidden cost of reduced civil liberties.
\end{abstract}

\section{Introduction}

The COVID-19 pandemic of 2020 has seen unprecedented measures by governments to restrict the movement and activities of both citizens and potential foreign visitors in order to curtail the virus. Measures to restrict the movement of the sick have long been common. During the times of the black plague in the $1600 \mathrm{~s}$, by some accounts the sick would be padlocked into their homes along with the healthy, and a cross painted over the door of the household in bright red, for any households in which even one individual had been infected [1]. But never before have the healthy been restricted in such numbers along with the sick [2].

\section{One-Sided Depiction of the Problem, Mass Fear, and Public Support of Authoritarian Control} Mathematical models for the spread of the pandemic may be driving this extreme response by some governments. However at least some of those mathematical models, by the admission of their own creators, don't take into consideration the deaths related to economic factors, and other factors that might be related to a reaction that is too extreme. In support of this conclusion, Ira Longini, a modeler at the University of Florida, says of such concerns "we should probably hook up with some economic modelers and try to factor that in" [3]. In the absence of this information, and with the lack of any welldefined methodology for distinguishing where extreme actions are irrational and where more moderate actions might be insufficient and might put the public at risk is a challenge. Mass fear is a natural consequence [4].

Observation of the spread of the virus has proven that the spread of COVID-19 is likely to kill people. However long lockdowns to slow the spread of any pandemic can also have catastrophic economic impacts that may themselves affect public health. "It's a three-way tussle," say Gabriel Leung, a modeler at the University of Hong Kong, "between protecting health, protecting the economy, and protecting people's well-being and emotional health" [3]. However, given that such models of the impact of economic factors on health and mortality already exist [5], [6], a more interesting question than understanding the economic impacts of shutdowns is understanding why such important 
information that already might exist, in many cases doe not appear to have been incorporated into public policy.

Because in support of Dr. Longini's concerns, past observation has proven that the hardship which might come from shutting entire economies down, as many are recommending in fear of the spread of COVID-19, might affect health and well-being to the point of killing people as well, particularly if that shutdown triggers economic collapse [7]. Given that economic collapse or the absence of economic collapse cannot be predicted with complete certainty, a great deal of caution is warranted [8]. Events in Venezuela leading up to the year 2020 prove how devastating an impact economic collapse can have on mortality rates [9], [10].

But even within relatively intact economies people are still killed by economic hardship. The number of people killed by economic hardship in the United States can be viewed from different perspectives:

\begin{tabular}{|l|l|}
\hline Category of Economic-Related Death in the US & Number Per Year \\
\hline Deaths of Despair & Estimated at 150,000 \\
\hline Lack of Healthcare & More than 26,000 \\
\hline Individual-level Poverty & 133,000 \\
\hline
\end{tabular}

Though there is still some degree of uncertainty about how lethal the COVID-19 pandemic actually is, even these numbers are potentially significant with respect to the mortality levels expected from the pandemic.

\section{Potential Indicators of Irrational Focus on Fear in the COVID-19 Response}

One overall estimate of the mortality rate of the COVID-19 virus is $0.66 \%$ [11]. But estimates vary. By some accounts the fatality rate for covid-19 in China appears to be as below [12]:

Age

80 and older

70 to 79

60 to 69

50 to 59

40 to 49

10 to 39

Children under 9 (reported)

\section{COVID-19 Mortality Rate}

$14.8 \%$

$8 \%$

$3.6 \%$

$1.3 \%$

$0.4 \%$

$0.2 \%$

$0 \%$

However, there is some reason to suspect that testing methodology might lead to systematic errors in these numbers [11]. Factors like the failure to test for immunity indicating the subject had contracted COVID-19 at any time, rather than presence of the live virus indicating the subject had COVID-19 at the time of testing, might lead to over reporting mortality. In addition, potential government reluctance to report actual mortality rates might lead to under reporting of mortality. Both contribute to uncertainty in the actual numbers.

If the covid-19 virus is indeed ten times worse than the flu as stated by some, and if the number of deaths in the US from the flu is approximately 41,000 per year [13], then the US might expect 410,000 deaths from covid-19. But by contrast, the number of cancer deaths in the US are 606,880 per year. Some suggest cancer deaths can certainly be reduced by over $50 \%$ more through lifestyle and other 
changes, resulting in a potential 300,000 lives per year. If this current concern over covid-19 is strictly a rational result of considering the risk, why not a similar effort for cancer?

Covid-19 is one of many coronaviruses that include the flu [14]. Even though flu vaccines exist no one has ever been able to "cure" the flu or any other coronavirus because of the number of strains due to their constant mutation. The consensus opinion among scientists appears to be that the covid-19 virus cannot be contained, and that all that can be done is to slow the spread so that healthcare facilities aren't overwhelmed [15]. By some estimates the majority of the population in the US will be exposed to the virus over the next year in any case. So even if staying withing the capacity of the health system to provide ventilators, staying within the capacity of the healthcare system to provide doctors, nurses, as well as masks, cleaning supplies, medications, and other necessities will save lives, when the capacity of the healthcare system is taken into account, what is the total difference in lives saved between the population getting exposed now and getting exposed over the course of a year? Does it amount to $98 \%$ of fatalities avoided? Does it amount to $2 \%$ of the fatalities avoided? At what point does the benefit in lives become more than the cost of the economic shutdown in lives?

Do these figures justify closing schools given the low mortality rate for pre-school or school aged children and teachers? Or do they justify taking special measures with elder care facilities? In the case of India, the shutdown of public railways and other transport with little notice was reputed to have forced scores of migrant workers to walk sometimes hundreds of kilometers back to their villages. Rather than remove them from exposure, this may have made that entire population more vulnerable [19], [20]. Perhaps a fitting reminder is that no one has ever been able to keep dry by mopping up the ocean. Better to stay out of the ocean oneself than waste all one's resources trying. Given the cost in terms of human lives that might be posed by economic collapse, is it worth examining other more targeted strategies in which the most vulnerable (perhaps those 60 and above) are kept isolated [16]?

\section{The Hidden Force towards Authoritarianism in the Absence of General Collective Intelligence}

A recently developed Functional Modeling Framework (FMF) theorizes the properties required for individual or collective cognition [17]. This framework has been used to develop a model of collective cognition (General Collective Intelligence or GCI). Since GCI in this framework is defined as having general problem solving ability, this model of GCI is proposed to be unique among group decisionmaking systems in having the capacity to reliably define and solve any general problem within human capacity to conceive. This is achieved through the ability to converge on selecting solutions that maximize collective outcomes in problem domains where other models are proposed to face potentially hidden constraints that might prevent them from having the capacity to converge on optimal solutions, or on any solutions at all [18]. Without collective intelligence to provide a balance of decentralization in decision-making, this theoretical model of GCI suggests all systems of decision-making have a high degree of (in some cases hidden) centralization because the mechanism for massive decentralization of all processes is simply lacking.

Centralization of in any group process, including those involved in research, manufacturing, or any other part of the life-cycle of any product or services, is projected to result in increasing inequality in favor of the process owner, and therefore decision-maker. In turn, increased resources as a result of increasing inequality facilitates greater ownership and control over more of these centralized decisionmaking processes. Because technology removes the constraints to storage and consumption of resources it also potentially removes the bounds to inequality so that the interests of the process owner (in this case the provider of the products and services), being unbounded, act as a "tax" that steadily shifts decision-making so that it drives decisions towards serving their interests. If centralized control is 
equivalent to authoritarianism, this hidden force towards greater centralized control is equivalent to a force towards authoritarianism.

\section{The General Relationship Between Mass Fear and Authoritarian Control}

The impact of mass fear is often for the citizenry to call for government leaders to take decisive action, which in turn requires control. And mass fear is very effective at encouraging a country's citizenry to cede that control in the hope of gaining protection [21], [22]. Restricting the movement and freedom of people at such an unprecedented scale as has occurred with the COVID-19 crisis may have introduced a level of state control over individual liberties that has not been seen in the history of mankind during peacetime [23] - [26]. History has shown us that once taken away, these liberties might not fully be restored. The level of autocratic control that is stable depends on many factors [27]. And the level of autocratic control that is maintainable with the current level of surveillance, big data, and other technology that enables the state to precisely target it's immense weight on individual citizens who are no longer anonymous may now be greater than ever. This increasing level of control by the state over the personal affairs of the individual also has a hidden cost in terms of human lives because there is no system of collective intelligence that ensures the decisions they make with all that power the citizenry gives up will be in the citizenry's best interests. Instead, the control the citizenry gives up may end up being used to do things decision-makers wanted to do anyways to serve their own vested interests [28].

\section{Inadvertently Fomenting Fear as the Path of Least Political Resistance}

Forces that systematically drive a reduction in civil liberties in response to fear and crisis do not need to be driven by any unprovable conspiracy theory. Such forces need not even be intentional. Whatever party is ruling during a time of fear-inducing crisis might lack any direct political or economic interests, either locally or internationally, which might be served by a more authoritarian regime. But even for cases in which this is true, focusing disproportionately on popular fears that tend to lead to more public support for authoritarian action might simply be the most expedient action in terms of increasing public support. Using the example of crime, as stated by Chevigny, P., "in democratic countries, at least in the western hemisphere, there has been a political trend toward appealing to the fear of crime as a popular issue in electoral campaigns, as well as more generally as a way of attracting public notice" [29]. In other words, when the public is prone to fixate on a given fear, that fear becomes the most effective channel of communication. And when the public is fearful, the best way of gaining public support is to take strong authoritarian action.

Elected politicians are in the end all engaged in a popularity contest. Even small nation-states with few or no multi-national business interests, are run by individuals who must seek re-election, either for themselves or their political allies. Trying to convince a population of the need for taking a balanced perspective in order to productively maximize collective well-being, rather than speaking to their unproductive fears, is not an effective strategy when no measures for success in the strategy of maximizing well-being exist.

\section{Fomenting Fear to Further Interests of the Ruling Elite}

In some cases however, national or international corporate interests of the political class or their allies might be perceived as having the potential to incentivize leaders to use fear to manipulate the population to serve a pre-existing agenda. One prominent example could potentially be the war with Iraq in which significant reluctance among the American population to go to war was overcome through the fear of "weapons of mass destruction" the populace was filled with. America didn't get safer by finding and removing any weapons. The weapons didn't exist. But to the misfortune of those who can only be thanked for having proudly served their country, America did manufacture a great many physically and mentally disabled veterans. If there is any truth in the assertion that some of 
America's decision-makers were in fact driven by interests in the oil, military contracts, and other business, as well as interests in regional control, which they and their cronies might have wanted in the first place, then exchanging the well-being of military men for such cynical goals shows how fear can be manipulated [29].

\section{The Cost of Authoritarianism}

As mentioned, without a system of collective intelligence to guide collective decision-making, the selfinterest of decision-makers is like a "tax" that constantly extracts value from all interactions. The more power decision-makers are given in a group decision-making system in which decisions can't be adapted to maximize collective well-being, the greater the cost of that tax in human lives. This tax is the cost of authoritarianism.

Assuming that a general collective intelligence has the capacity to find any strategy or other intervention with the capacity to maximize efficiency at achieving collective well-being per capita per unit of resources, then the cost of this authoritarianism can potentially be assessed by assessing the cost of the current ineffectiveness of governance [30] -[33].

\section{Conclusions}

In general, reductions in civil liberties might occur due to an increase in anarchy in which case control flows from the individual to no one, or due to an increase in authoritarianism, in which case control flows from the individual to some entity. In the case of an increase in authoritarian control, that control might be given up by the citizenry in the course of seeking protection from some immediate threat. However authoritarian control as a decision-making system may tend to be aligned with the interests of those in control of decision-making. And the misalignment of their interests with the collective wellbeing has a cost. Systems of General Collective Intelligence are designed to use the reasoning strategies available to them to maximize collective well-being. This cost, the difference between decisions that maximize collective well-being, and decisions that maximize the interests of those decision-makers, is a natural consequence of all group decision-making systems that lack general collective intelligence. And as decision-making continues to further centralize in the absence of GCI, this cost may continue to increase.

The "change engine" theory of GCI suggests that a wide range of collective impacts, including potentially existential challenges like the Sustainable Development Goals, are not reliably achievable without GCI. This theory also suggests that GCI can make these impacts reliably self-funding, so that these impacts are reliably achievable at a scale large enough to be transformative. Given that the United Nations estimates a \$23 trillion USD gap between the funding required to achieve the SDGs, and the funding that is available to do so, if GCI is capable of bridging this gap as believed, the value of being able to implement GCI is at least that $\$ 23$ trillion.

For this reason, the most important cost of authoritarianism is that as a centralized system of decisionmaking, it has the potential to make a largely decentralized system of decision-making like GCI impossible unless the potentially one single entity in charge of that authority wishes to implement it. And in such an authoritarian system the support of any such single entity might be statistically difficult to gain since the lack of GCI is measurably outside the tendency for any individual entity to see as a problem, and since GCI itself is measurably outside the tendency of any individual entity to see as a solution. That support might even be impossible if GCI is outside the capacity of the required individual entity to see as a problem or as a solution. 
GCI is a system with the capacity to optimize collective well-being per unit of natural and other resources. If a given standard of well-being is being targeted with a given amount of such resources, the theory suggests that GCI is required to have the capacity to reliably achieve that standard of collective well-being. Mathematically, if well-being is a function of resources per capita, the only other way to reliably achieve a given standard of collective well-being is to reduce the population. One might believe their are too many people on the earth anyway, but such a population reduction might require much more authoritarian governance. One might welcome such authoritarian governance from the point of view that if that entity was benevolent, governance by a benevolent entity would be a positive for a law abiding citizen regardless of whether that entity was authoritarian. However, the theory of GCI suggest that any authoritarian entity that does not implement GCI can't optimize well-being, and therefore by definition has interests that are not aligned with the maximization of collective well-being, and cannot be benevolent.

When assessing the cost of a reduction in civil liberties, rather than assessing the cost of government ineffectiveness as a measure of the difference between collective well-being achieved and maximum collective well-being, a much more manageable task is then to assess the cost of achieving the SDGs where the cost of achieving them can't be covered otherwise. In other words, a simpler way of assessing the cost of a reduction in civil liberties is by equating that cost to the $\$ 23$ trillon SDGs funding gap.

\section{References}

[1] Evelyn Lord. The Great Plague: A People's History. New Haven and London: Yale University Press, 2014.

[2] Xiaoke Xu, Xiaofan Liu, Lin Wang, Sheikh Taslim ALI, Zhanwei Du, Paolo Bosetti, Benjamin J Cowling, Ye Wu, Household transmissions of SARS-CoV-2 in the time of unprecedented travel lockdown in China, medRxiv 2020.03.02.20029868; doi: https://doi.org/10.1101/2020.03.02.20029868 [3] Martin Enserink, Kai Kupferschmidt, Mathematics of life and death: How disease models shape national shutdowns and other pandemic policies, Published Mar. 25, 2020, 6:40 PM, Accessed Mar. 30, 2020 from: https://www.sciencemag.org/news/2020/03/mathematics-life-and-death-how-diseasemodels-shape-national-shutdowns-and-other\#

[4] David L. Altheide, Creating Fear: News and the Construction of Crisis, Transaction Publishers (2002), ISBN:0202365263, 9780202365268

[5] Ruhm, C. J. ( 2016) Health Effects of Economic Crises. Health Econ., 25: 6- 24. doi: $10.1002 /$ hec. 3373 .

[6] Gerard J. van den Berg, Alexander Paul and Steffen Reinhold, Economic conditions and the health of newborns: Evidence from comprehensive register data, Labour Economics, 10.1016/j.labeco.2020.101795, (101795), (2020).

[7] Kristín Helga Birgisdóttir, Arna Hauksdóttir, Christopher Ruhm, Unnur Anna Valdimarsdóttir and Tinna Laufey Ásgeirsdóttir, The effect of the economic collapse in Iceland on the probability of cardiovascular events, Economics \& Human Biology, 10.1016/j.ehb.2020.100861, (100861), (2020). [8] Spyros Makridakis, Robin M. Hogarth, Anil Gaba, Forecasting and uncertainty in the economic and business world, International Journal of Forecasting, Volume 25, Issue 4, 2009, Pages 794-812, ISSN 0169-2070, https://doi.org/10.1016/j.ijforecast.2009.05.012.

[9] Hotez, P. J., Basáñez, M. G., Acosta-Serrano, A., \& Grillet, M. E. (2017). Venezuela and its rising vector-borne neglected diseases. PLoS neglected tropical diseases, 11(6), e0005423. https://doi.org/10.1371/journal.pntd.0005423

[10] Kathleen R Page, Shannon Doocy, Feliciano Reyna Ganteaume, Julio S Castro, Paul Spiegel, Chris Beyrer, Venezuela's public health crisis: a regional emergency, The Lancet, Volume 393, Issue 10177, 2019, Pages 1254-1260, ISSN 0140-6736, https://doi.org/10.1016/S0140-6736(19)30344-7. 
[11] Mahase Elisabeth. Covid-19: death rate is $0.66 \%$ and increases with age, study estimates BMJ 2020; $369: \mathrm{m} 1327$

[12] Max Roser, Hannah Ritchie and Esteban Ortiz-Ospina (2020) - "Coronavirus Disease (COVID-19) - Statistics and Research". Published online at OurWorldInData.org. Retrieved from:

'https://ourworldindata.org/coronavirus' [Online Resource]

[13] Noelle-Angelique M. Molinari, Ismael R. Ortega-Sanchez, Mark L. Messonnier, William W.

Thompson, Pascale M. Wortley, Eric Weintraub, Carolyn B. Bridges, The annual impact of seasonal influenza in the US: Measuring disease burden and costs, Vaccine, Volume 25, Issue 27, 2007, Pages 5086-5096, ISSN 0264-410X, https://doi.org/10.1016/j.vaccine.2007.03.046.

[14] Woo, P.C.Y.; Huang, Y.; Lau, S.K.P.; Yuen, K.-Y. Coronavirus Genomics and Bioinformatics Analysis. Viruses 2010, 2, 1804-1820.

[15] Jon Cohen, Kai Kupferschmidt, Countries test tactics in 'war' against COVID-19, Science 20 Mar 2020: Vol. 367, Issue 6484, pp. 1287-1288, DOI: 10.1126/science.367.6484.1287

[16] Herd immunity - estimating the level required to halt the COVID-19 epidemics in affected countries, KWOK, Kin On et al., Journal of Infection, Volume 0, Issue 0

[17] Andy E. Williams, A Functional Modeling Framework for Representing and Comparing Models of Consciousness or Cognition, under review

[18] Andy E. Williams, General Collective Intelligence and the Constraints to Group Decision-Making, under review

[19] Modi seeks 'forgiveness' from India's poor over COVID-19 lockdown, Published Mar. 30, 2020, 6:40 PM, Accessed Mar. 30, 2020 from: https:/www.aljazeera.com/news/2020/03/modi-seeks-

forgiveness-india-poor-covid-19-lockdown-200329132107033.html

[20] Chaos and hunger amid India coronavirus lockdown, Published Mar. 27, 2020, 6:40 PM, Accessed Mar. 30, 2020 from: https://www.aljazeera.com/news/2020/03/chaos-hunger-india-coronaviruslockdown-200327094522268.html

[21] Altheide, D. L. (2006). Terrorism and the Politics of Fear. Cultural Studies $\leftrightarrow$ Critical

Methodologies, 6(4), 415-439. https://doi.org/10.1177/1532708605285733

[22] Psychology of Terrorism, edited by Professor Pacific Graduate School of Psychology Consulting Professor of Psychiatry and Behavioral Sciences Bruce Bongar, PhD, Bruce Michael Bongar, Larry E. Beutler, Lisa M. Brown, Wm McInnes Distinguished Professor Emeritus of Clinical Psychology Larry E Beutler, PhD, Philip G. Zimbardo, James N. Breckinridge, Professor of Psychology and Director of Training James N Breckenridge, Oxford University Press (2007), ISBN: 0195172493,9780195172492 [23] Wu Z, McGoogan JM. Characteristics of and Important Lessons From the Coronavirus Disease 2019 (COVID-19) Outbreak in China: Summary of a Report of 72314 Cases From the Chinese Center for Disease Control and Prevention. JAMA. 2020;323(13):1239-1242. doi:10.1001/jama.2020.2648 [24] Gostin LO, Hodge JG. US Emergency Legal Responses to Novel Coronavirus: Balancing Public Health and Civil Liberties. JAMA. 2020;323(12):1131-1132. doi:10.1001/jama.2020.2025

[25] Adalja AA, Toner E, Inglesby TV. Priorities for the US Health Community Responding to COVID19. JAMA. Published online March 03, 2020. doi:10.1001/jama.2020.3413

[26] Gostin LO, Hodge JG, Wiley LF. Presidential Powers and Response to COVID-19. JAMA. Published online March 18, 2020. doi:10.1001/jama.2020.4335

[27] Maria Brouwer, Governance and Innovation: A Historical View, Routledge, 10 Mar 2008 [28] James McCartney, Molly Sinclair McCartney, America's War Machine: Vested Interests, Endless Conflicts, Macmillan, 2015, ISBN: 1466878762, 9781466878761

[29] Chevigny, P. (2003). The populism of fear: Politics of crime in the Americas. Punishment \& Society, 5(1), 77-96. https://doi.org/10.1177/1462474503005001293

[30] Imundo, L. V. (1975). Ineffectiveness and Inefficiency in Government Management. Public Personnel Management, 4(2), 90-95. https://doi.org/10.1177/009102607500400203 
[31] Blane D. Lewis (2006) Local government taxation: An analysis of administrative cost inefficiency, Bulletin of Indonesian Economic Studies, 42:2, 213-233, DOI: 10.1080/00074910600873666

[32] Worthington, A.C. (2000), Cost Efficiency in Australian Local Government: A Comparative Analysis of Mathematical Programming anf Econometrical Approaches. Financial Accountability \& Management, 16: 201-223. doi:10.1111/1468-0408.00105

[33] Duncombe, W., Miner, J. \& Ruggiero, J. Empirical evaluation of bureaucratic models of inefficiency. Public Choice 93, 1-18 (1997). https://doi.org/10.1023/A:1017910714756 